\title{
Labyrinthe
}

20 | 2005 (1)

La Cognition

\section{Co-définir la culture et la nature}

Vers des collaborations symétriques à l'interface des sciences cognitives et des sciences sociales

Jacques Plouin

\section{(2) OpenEdition}

Journals

Édition électronique

URL : http://journals.openedition.org/labyrinthe/758

DOI : $10.4000 /$ labyrinthe.758

ISSN : 1950-6031

Éditeur

Hermann

Édition imprimée

Date de publication : 20 avril 2005

Pagination : 67-75

Référence électronique

Jacques Plouin, "Co-définir la culture et la nature », Labyrinthe [En ligne], 20 | 2005 (1), mis en ligne le 26 juin 2008, consulté le 10 décembre 2020. URL : http://journals.openedition.org/labyrinthe/758 ;

DOI : https://doi.org/10.4000/labyrinthe.758

Propriété intellectuelle 


\section{CO-DÉFINIR LA CULTURE ET LA NATURE \\ Vers des collaborations symétriques à l'interface des sciences cognitives et des sciences sociales*}

Jacques Plouin

jacques.plouin@hotmail.com

Les entraves aux échanges entre sciences cognitives et sciences sociales ressortissent, d'après un certain nombre de spécialistes des premières, aux résistances de ceux des secondes. L'analyse des arguments cognitivistes montre cependant que les obstacles tiennent également aux conséquences épistémologiques d'un dialogue véritablement symétrique: si les sciences cognitives peuvent co-définir la culture, les sciences sociales sont alors elles-mêmes en position de co-définir la nature et la connaissance.

\section{Sciences sociales : les grandes muettes?}

L'indifférence parfois hostile des sciences sociales à l'égard des sciences cognitives confère une apparence de vraisemblance à l'opinion, souvent avancée par les «cognitivistes ${ }^{1}$ », selon laquelle les sciences cognitives innovent et proposent là où les sciences sociales refusent et regimbent. Il n'en convient pas moins de se demander pourquoi il n'y a, en matière de dialogue, presque rien plutôt que quelque

\footnotetext{
* Cet article s'inscrit dans le cours d'un doctorat de philosophie, sous la direction de P. Livet, à l'université d'Aix-Marseille-I, où Jacques Plouin est rattaché au Ceperc (Centre d'épistémologie et d'ergologie comparatives). Sa thèse, dont la soutenance est prévue pour 2005, porte, de manière générale, sur les pratiques de discipline, à l'intersection de la philosophie et de la théorie sociale.

1. Le terme est de manipulation délicate, tant sont variés les domaines où évolue la cognition. L'usage du terme se restreint si l'on considère qu'il s'agit de désigner les chercheurs qui travaillent autour de quelques hypothèses communes. Pour les besoins de l'article, «cognitiviste » désignera de façon idéaltypique, c'est-à-dire, générale et particulière, les tenants des hypothèses les plus proches du pôle «innéiste» de la cognition.
} 
chose. À quoi tient le refus supposé des sociologues ${ }^{2}$ ? L'interprétation la plus commune veut que les sciences sociales se refusent à admettre une incursion de la nature dans leur territoire, la culture. Les choses sont-elles aussi simples?

\section{Effets d'échelles}

En deçà de la question du rôle de la nature, au sein de la culture, c'est sans doute la conception de celle-ci qui est d'abord en jeu. Les cognitivistes font souvent dépendre leurs relations avec les sciences sociales de l'acceptation de notions telles que l'innéité ou la nature humaine ${ }^{3}-$ qui, si elles ne sont pas toujours explicitement thématisées, sont conceptuellement obvies : par exemple la croyance au caractère invalidant de l'accusation de relativisme. Ces notions ne sont l'apanage que de cognitivistes - l'innéité est ainsi un postulat de certaines écoles linguistiques, pas de toutes -, mais leur revendication est souvent un motif de défiance générale pour nombre de sociologues qui y voient peu d'intérêt empirique et beaucoup de présupposés philosophiques.

Examinées à l'aune des sciences sociales, ces notions d'innéité ou de nature humaine sont problématiques, car elles ont pour effet de placer le cerveau humain en position d'absolu. $\mathrm{Si}$ «inné», par exemple, signifie «tout ce qui est virtuellement disponible à l'origine », on soulignera cependant - en se rappelant que le cerveau, comme toute construction naturelle, a une histoire - que l'important n'est sans doute pas tant de découvrir la «nature naturelle» du cerveau pur que d'identifier l'échelle relative des processus étudiés, qu'ils soient «naturels» ou «culturels», ou les deux. L'innéité ou la nature humaine ont le défaut d'être corrélées à l'idée que les processus essentiels se déroulent à une échelle temporelle qui échappe aux prises de la société et de la culture et qui est tenue pour indispensable à l'étude des phénomènes humains ${ }^{4}$. Ces notions ressortissent à une forme de cécité «scalaire»

2. Il ne sera pas, ici, fait de distinction réelle entre les différents spécialistes des sciences sociales.

3. La diversité des sciences cognitives ou même simplement le titre d'ouvrage cognitiviste parmi d'autres, Not By Genes Alone, par exemple, interdisent d'affirmer que tous les cognitivistes sont des « innéistes » ou des « naturistes ». Cependant, le chercheur en sciences sociales ne saura ignorer, à travers un tel titre, qu'il est sommé de prendre part à un débat qui, au fond, a très peu d'incidences sur la définition même de ses terrains.

4. Cette forme de cécité aux effets d'échelle explique pour partie l'opinion selon laquelle l'étude des phénomènes sociaux devrait être systématiquement précédée de celle des phénomènes cognitifs. 
qui fait croire que «one scale fits all». Or, il n'y a pas d'échelle plus réelle qu'une autre.

Certes les sciences cognitives sont en mesure de décrire les conditions générales d'une grande partie du comportement cérébro-spinal ${ }^{5}$. Mais les sciences sociales travaillent à d'autres échelles, dont certaines leur sont spécifiques. Comme Max Weber le notait, «dans les sciences de la culture, la connaissance du général n'a jamais d'importance pour elle-même ${ }^{6} »$. Émile Durkheim, dès les premières pages des Règles ${ }^{7}$, affirme exactement la même chose. Les sciences sociales ne sont pas des recherches d'origines. Nul anthropologue ne niera que la plupart des primates humains viennent au monde dotés d'un cerveau-type qui répond à des fonctionnements biologiques montés au cours d'une évolution d'échelle quasi géologique. Ce qui est contestable, en revanche, c'est l'idée qu'une échelle particulière soit imposée comme plus significative que d'autres. L'échelle de la décade ou de l'année n'est pas moins une échelle que celle du milliard d'années. Toutes les échelles de travail se valent.

Le centre de gravité de cette affirmation n'est évidemment pas la valeur, mais le travail. Une échelle de travail ne renvoie pas à des questions ontologiques mais à des problèmes méthodologiques. Sans cette distinction, on verse dans le sophisme selon lequel les sciences sociales sont quasiment solubles dans les sciences cognitives en raison de la nature naturelle des humains à l'état naturel. Sous des apparences de déduction logique, on déguise une équation douteuse, voire complètement fausse, entre la nature des objets étudiés et les techniques d'étude de ces objets. Autant vouloir affirmer que l'étude de la chimie est impossible tant que l'on n'a pas achevé celle de la physique quantique. La seule réponse que l'on pourra faire aux arguments de cette nature est que les sciences sociales sont maîtresses de la pertinence de leurs méthodes. Que les sciences cognitives puissent constituer une ressource de méthodes et de données est donc indéniable, mais les thèses de Weber et de Durkheim sont fondatrices du «raisonnement sociologique », en ce qu'elles assument l'importance de leur rapport à

\footnotetext{
5. On épargnera au lecteur une analyse critique du choix de la connaissance comme comportement neurologique emblématique.

6.Voir Essais sur la théorie de la science, Paris, Plon, édition Pocket, 1965 (1992), p. 159.

7. Les Règles de la méthode sociologique (1895), Puf, édition Quadrige, Paris, 1937 (1993), ch. 1, p. 3-6.
} 
l'historicité ${ }^{8}$ et font de la généralité une variable de l'explication, pas sa fin'.

\section{Qui définit quoi}

En somme, les sciences sociales exercent le droit de formuler leur propre «hypotheses non fingo». Tout n'est pas évident dans les postulats des sciences sociales, et bien des épistémologues continuent de s'interroger sur la nature des faits sociaux durkheimiens ou celle de l'idéaltype weberien. Mais ces questions ne sont pas opératoires: ce sont des étais à théorie, pas des théories. Dès lors, certaines «offres» cognitivistes se révèlent impraticables. Ainsi, Dan Sperber, promoteur zélé, pourtant, du dialogue entre sciences cognitives et sciences sociales, propose la règle suivante aux anthropologues: «Ne reconnaissez pas un phénomène tant que votre compréhension de son existence matérielle est insuffisante pour lui attribuer des pouvoirs causaux ${ }^{10}$. » $\mathrm{La}$ règle semble raisonnable. Mais elle relève tout juste du sens commun. À suivre de telles règles, ni Galilée, dont les affirmations, violaient directement le concept scientifique de matière, ni Darwin, dont la théorie suppose des mécanismes de mutation inconnus à son époque, n'auraient été légitimés à émettre leurs théories scientifiques. Il faut l'avouer, les problèmes ontologiques soulevés par la nature du fait social forment une objection assez faible au regard de sa fécondité empirique et théorique.

Que conclure, sinon que certains cognitivistes ont le plus grand mal à identifier les sciences sociales dans leur autonomie scientifique? L'assertion paraîtra abrupte, mais elle éclaire la nature hiérarchique des relations que les sciences cognitives espèrent proposer aux sciences sociales. Ainsi, The Blank Slate, ouvrage de Steven Pinker, sous-titré «le déni moderne de la nature humaine» (sic), fait régulièrement passer pour des prises de positions idéologiques - voire sentimentales, lors-

\footnotetext{
8. Entendue au sens de « contingence» : il ne s'agit pas de pratiquer un réductionnisme qui ferait de toute science sociale une forme d'histoire et renverrait aux aspects les moins féconds du débat de la structure et de l'histoire.

9. C'est la thèse du «raisonnement sociologique» de Jean-Claude Passeron développée dans Le Raisonnement sociologique, Nathan, Paris, 1991.

10. Dan Sperber, «Quelques outils conceptuels pour une science naturelle de la société et de la culture », dans Raisons pratiques. L'enquête ontologique (Livet, P. et Ogien, R. éd.), Paris, EHESS, 2000.
} 
qu'il évoque le rejet de l'ethnocentrisme au nom d'une affection pour les «nobles sauvages »-ce que les sciences sociales identifient comme des questions de méthodes. Durkheim est, selon Pinker, au comble de l'erreur lorsqu'il affirme qu'un fait social s'explique par un autre fait social. En rejetant cette proposition, on récuse en fait la possibilité non seulement d'une explication spécifiquement sociologique, mais, de manière plus profonde, l'idée même d'un objet scientifique propre aux sciences sociales. Cela est patent lorsqu'on lit qu' «un fait social dépend entièrement du désir qu'on a de le traiter comme un fait ${ }^{11} \gg-$ où le social est confondu avec le performatif - ou encore, chez Dan Sperber, qu'une approche naturaliste de la culture «doit, dans tous les cas, combiner une perspective environnementale et une perspective psychologique, et [qu'] elle n'est pas obligée - ni empêchée non plus - de privilégier l'une ou l'autre de ces deux perspectives ${ }^{12}{ } \gg-$ où le choix exclusif entre deux perspectives récuse l'idée d'objets et d'échelles spécifiquement sociologiques. De telles affirmations semblent tout droit sorties de la préhistoire des sciences sociales.

Ces éléments invitent à penser que la complainte des cognitivistes face à l'attitude des sciences sociales masque parfois un refus de transiger sur plusieurs points, notamment le préjugé selon lequel le social serait un «explicandum» et non un «explicans ». On voit mal les gains que les sciences sociales pourraient espérer de propositions dont les principes philosophiques conduisent à ignorer leur existence épistémologique (elles ne sont presque reconnues que sur le plan institutionnel), leurs débats et leur histoire.

\section{Durkheim et le versant naturaliste du raisonnement sociologique}

L'histoire des débats sociologiques, en particulier, est souvent négligée. Ainsi, nombre de cognitivistes assimilent la circonspection des

\footnotetext{
11. " social fact depends entirely on the willingness of people to treat it as a fact », dans The Blank Slate de Steven Pinker, Londres, Penguin Books, 2002, p. 65. C'est moi qui souligne.

12. Op. cit. (c'est moi qui souligne). L'argument de Dan Sperber est, à ce point de vue, déconcertant, puisqu'il reconnaît ailleurs que la collaboration interdisciplinaire ne peut se faire que sur des objets particuliers et non au prix de remises en cause d'échelle paradigmatique. Voir Dan Sperber, «Naturaliser l'esprit», dans Des idées qui viennent (Roger Pol-Droit et Dan Sperber éditeurs), Paris, Odile Jacob, 1999, p. 11-24.
} 
sciences sociales envers la biologie et la psychologie à un antinaturalisme. Or, une chose est de constater que bien des anthropologues ou sociologues rejettent le naturalisme, une autre est d'ignorer la nature des débats internes à ces disciplines. Une telle négligence est dommageable, car elle induit, notamment, des impasses sur les travaux de Durkheim où l'affirmation de l'autonomie des sciences sociales passe précisément par l'affirmation d'un naturalisme sociologique. Inséparable d'une démarcation d'avec les sciences biologiques et psychologiques, ce naturalisme sociologique peut donc constituer une plate-forme de débat à l'interface de ces disciplines. La tradition durkheimienne n'a jamais nié l'importance des déterminismes «matériels »- Durkheim constate ainsi que l'actualisation d'un fait social ne peut jamais s'étendre à l'ensemble d'une société en raison de la diversité des organismes biologiques ${ }^{13}$-, mais elle récuse qu'ils puissent être substitués à des déterminismes sociaux.

Certes les thèses de Durkheim n'ont, pas plus que celles de Weber, jamais fait l'unanimité dans les sciences sociales, mais elles démontrent que le naturalisme est d'abord un problème interne aux sciences sociales, car il est, dès le départ, une option de leur boîte à outils. Sur ces questions, ce serait une illusion de penser que les lieux d'interface avec les sciences cognitives devraient être créés de toutes pièces et aux dépens des seules sciences sociales. Le travail interdisciplinaire ne peut pourtant pas être formulé dans les termes d'une naturalisation des sciences sociales, car celles-ci sont largement en mesure de fournir une tradition naturaliste ainsi que des concepts critiques de cette tradition. Dan Sperber ${ }^{14}$ se fait lui-même l'écho de cette tradition lorsqu'il évoque la fécondité des travaux de l'anthropologue Jack Goody ${ }^{15}$ sur les «"technologies" de l'intellect» (qui désignent des phénomènes tels que l'écriture, l'imprimerie, les calculateurs), notion très bien faite pour constituer une interface concrète, opératoire et adaptée au no man's land épistémologique où se tutoient les marches respectives du social et du bio-psychologique.

13. Op. cit., chapitre 3.

14. Voir « L'individuel sous l'influence du collectif » dans La Recherche, $\mathrm{n}^{\circ}$ 344, juillet-août 2001, p. 32-35.

15. Entamés notamment avec La Raison graphique, traduction de The Domestication of the Savage Mind. 
Au sein de la tradition durkheimienne, on évoquera également les ressources offertes par l'œuvre de Mauss, qui ne manqua jamais d'appeler à la collaboration des sociologues et des psychologues. Mauss est également l'auteur de concepts directement destinés aux collaborations débattues ici, telle que «l'expression obligatoire des sentiments» ou, de manière plus large encore, les «techniques du corps ${ }^{16}$. Cette dernière notion conduit à insérer un plan d'explication sociologique dans la description du comportement bio-psychologique des individus: les variations dans la forme et l'usage du «corps-esprit» relèvent de déterminations qui ne tiennent pas aux seuls accidents individuels. L'effet de ce concept est de récuser le recours à des dichotomies $a$ priori, incontrôlées et incontrôlables, telles que celle du corps et de l'esprit, qui assimile systématiquement le corps à du «naturel» et sa diversité phénoménale à des accidents individuels. Ces dichotomies n'ont, la plupart du temps, de signification pour les sciences sociales que comme prénotions à circonvenir et à intégrer à l'objet d'enquête : le vrai travail commence dans l'étude des usages réels et systématiques de ces dispositifs culturels. Là encore, tout est relatif... à l'échelle des phénomènes considérés. La notion de technique du corps trouble peutêtre l'ordre des préjugés philosophiques, mais elle ouvre à l'enquête empirique. Ce qui est tout ce que l'on peut demander à un concept scientifique.

\section{Vers une épistémologie symétrique?}

La constitution d'interfaces robustes entre sciences sociales et sciences cognitives ne peut être féconde que si elle induit un double mouvement de co-définition de la nature et de la culture. D'un côté, les sciences sociales devraient constater que la culture peut partiellement se définir en termes éthologiques, neurologiques ou évolutionnistes: des recherches stimulantes dans ces domaines soulèvent des questions intéressantes ${ }^{17}$. De leur côté, les cognitivistes devraient constater que la définition de la nature ne peut être le monopole des sciences dites de la nature. Disons-le nettement, la co-définition de la nature est celle qui

\footnotetext{
16. Ces concepts sont présentés, notamment, dans Sociologie et anthropologie, Paris, Puf, édition Quadrige, 1950 (1995).

17. Les travaux de Robert Boyd et Peter Richerson, dont Not By Genes Alone mentionné plus haut, en font partie.
} 


\section{Labyrinthe, $n^{\circ} 20$}

risque de rencontrer le plus de résistance, car elle suppose - en s'inspirant du sous-titre d'un essai de Bruno Latour ${ }^{18}$ - une "épistémologie symétrique », qui n'accorde de primat ontologique ou épistémologique à aucun ordre de science. Symétrie pour symétrie, les réactions de certains sociologues à l'encontre des incursions cognitivistes dans le domaine de la culture et de la société sont équivalentes à la levée de bouclier que suscite, chez certains philosophes et scientifiques ${ }^{19}$, la redéfinition de la nature par la sociologie de la connaissance, dont l'origine remonte en outre aux travaux de Durkheim sur les religions. Les interfaces existent mais ce sont encore des chantiers.

\section{REPÈRES BIBLIOGRAPHIQUES}

Boyd Robert et Richerson Peter, Not by Genes Alone: How Culture Transformed Human Evolution, University of Chicago Press, Chicago, 2004.

Durkheim Émile, Les Règles de la méthode sociologique (1895), Puf, édition Quadrige, Paris, 1937 (1993).

Goody Jack, La Raison graphique, Paris, Minuit, 1979.

Gross Paul, LeVITT Norman et LewIS Martin, The Flight from Science and Reason, New York, New York Academy of Sciences, 1996.

Latour Bruno, Nous n'avons jamais été modernes. Essai d'anthropologie symétrique, Paris, La Découverte, 1997.

Mauss Marcel, Sociologie et Anthropologie, Paris, Puf, édition Quadrige, 1950 (1995).

PASSERON Jean-Claude, Le Raisonnement sociologique, Paris, Nathan, 1991.

18. Nous n'avons jamais été modernes. Essai d'anthropologie symétrique, Paris, La Découverte, 1997. 19. On consultera, par exemple, les arguments présentés contre les positions théoriques de Latour (les travaux empiriques n'étant, comme à l'habitude, pas vraiment abordés...) dans l'ouvrage The Flight from Science and Reason, édité par Gross et al., New York, The New York Academy of Science, 1996, p. 257-297. 
Pinker Steven, The Blank Slate, Londres, Penguin Books, 2002.

SPERBER Dan, «Quelques outils conceptuels pour une science naturelle de la société et de la culture », dans Raisons pratiques. L'enquête ontologique (Livet Pierre et Ogien Ruwen éditeurs), Paris, EHESS, 2000. -, «L'individuel sous l'influence du collectif », La Recherche, n 344, juillet-août 2001.

Weber Max, Essais sur la théorie de la science, Paris, Plon, édition Pocket, 1965 (1992). 